\title{
The utility of $\alpha$-synuclein as biofluid marker in neurodegenerative diseases: a systematic review of the literature
}

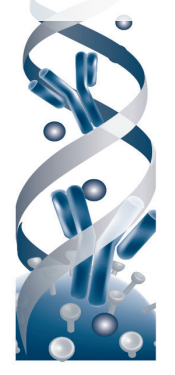

The discovery of $\alpha$-synuclein ( $\alpha$-syn) as a major component of Lewy bodies, neuropathological hallmark of Parkinson's disease (PD), dementia with Lewy bodies and of glial inclusions in multiple system atrophy initiated the investigation of $\alpha$-syn as a biomarker in cerebrospinal fluid (CSF). Due to the involvement of the periphery in PD the quantification of $\alpha$-syn in peripheral fluids such as serum, plasma and saliva has been investigated as well. We review how the development of multiple assays for the quantification of $\alpha$-syn has yielded novel insights into the variety of $\alpha$-syn species present in the different fluids; the optimal preanalytical conditions required for robust quantification and the potential clinical value of $\alpha$-syn as biomarker. We also suggest future approaches to use of CSF $\alpha$-syn in neurodegenerative diseases.

Keywords: $\alpha$-synuclein $\bullet$ biomarker $\bullet$ CSF $\bullet$ diagnosis $\bullet$ ELISA $\bullet$ Parkinson's disease

In parallel to the measurement of proteins in cerebrospinal fluid (CSF) related to Alzheimer's disease (AD), namely, total and phosphorylated tau protein and $\beta$-amyloid $1-42$, the quantification of $\alpha$-syn in biological fluids as a biomarker of $\alpha$-syn-related neurodegenerative disorders has gained much attention in the last years. The discovery of $\alpha$-syn as a major component of Lewy bodies (LBs), the neuropathological hallmark of Parkinson's disease (PD) and dementia with Lewy bodies (DLB) as well as of glial inclusions in multiple system atrophy (MSA) initiated the investigation of $\alpha$-syn as a biomarker. Due to the proximity of CSF to the CNS, this biofluid has been investigated primarily, but recent studies have also shown the presence of $\alpha$-syn in peripheral fluids, likely due to the involvement of peripheral organs in $\mathrm{PD}$ [1].

A diagnostic biomarker to improve the early and more accurate diagnosis of PD would be of tremendous importance for early diagnosis and clinical trials. Currently, the diagnosis of PD according to the UK Brain Bank Criteria is made when $70 \%$ of dopaminergic neurons are already degenerated. The clinical diagnosis based on motor symp- toms is too inaccurate with $15-25 \%$ misdiagnoses [2].

Furthermore, a progression marker would be of utmost importance to objectively monitor disease progression for upcoming clinical trials with putative neuroprotective agents, where clinical (mainly motor) rating scales have failed.

Finally a prognostic marker for different clinical phenotypes (e.g., early cognitive decline) would improve patient care.

Therefore the first studies on the presence of $\alpha$-syn in CSF [3] were welcomed by the scientific community but were hampered by insensitivity of the first assays, discrepant findings depending on assay formats, tremendous overlap of single values in patients and controls and the emerging knowledge on the important pre-analytical handling of fluids for robust and reliable quantification [4].

We will summarize the current knowledge and developments as well as the interpretation and limitations for the clinical value of $\alpha$-syn in CSF and give a future directive on where the field should move with respect to the current limitations in the analysis
Anja Hviid Simonsen ${ }^{\ddagger}$, Bea Kuiperij ${ }^{\ddagger}$, Omar Mukhtar Ali El-Agnaf, Sebastian Engelborghs, Sanna-Kaisa Herukka, Lucilla Parnetti, Irena Rektorova, Eugeen Vanmechelen, Elisabeth Kapaki, Marcel Verbeek \& Brit Mollenhauer*

*Author for correspondence: brit.mollenhauer@paracelsus-kliniken.de *These authors contributed equally For full author list, please see last page
Future
Medicine $\mathrm{fS}$ par of 
of $\alpha$-syn as a biofluid marker for neurodegenerative diseases.

\section{Methods for systematic review}

\section{Search strategy \& selection process}

A PubMed search (until December 2014) was performed using the following search terms: (cerebrospinal fluid OR CSF) AND diagnosis* AND (alpha synuclein OR synuclein).

Only publications in English that investigated human subjects were evaluated.

Additionally, the reference lists of the retrieved publications were searched for relevant publications. Reviews were excluded.

A total of 113 publications were found and screened. After deleting reviews, opinion papers and irrelevant publications, 56 publications remained in which quantification of $\alpha$-syn levels in patients with neurodegenerative diseases were reported.

Irrelevant publications were ones in which $\alpha$-syn levels were only measured in brain tissue as well as genetic studies or studies on patients with other diseases. Since postmortem sampled ventricular CSF will not be comparable to studies on lumbar CSF $\alpha$-syn [4], an additional three papers were excluded. Therefore, 53 papers were evaluated in this review (Figure 1).

\section{Analytical aspects}

\section{Description of antibodies for full length $\alpha$-syn}

$\&$ its splice variants

Different ELISA-based immunoassays have been employed to quantify $\alpha$-syn in biological fluids, especially CSF, with varying results. In general, the assays detecting monomeric isoforms of $\alpha$-syn differ from each other for the used antibody combinations and the splice variants of $\alpha$-syn that are detected. $\alpha$-Syn may appear in four isoforms, in other words, $\alpha$-syn98, $\alpha$-syn112, $\alpha$-syn126 and $\alpha$-syn140, based on alternative splicing of exon 3 and 5, of which the largest isoform, $\alpha$-syn140, is the most abundant isoform in the brain $[5,6]$.

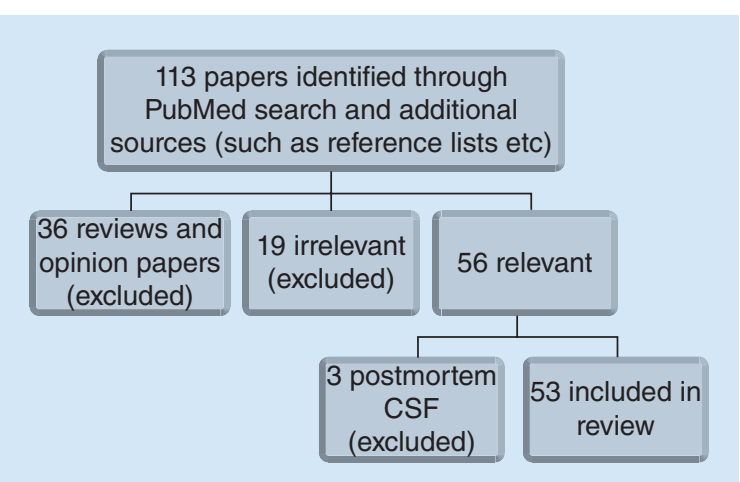

Figure 1. Literature search flowchart.
Figure 2 provides an overview of the epitopes within $\alpha$-syn that are recognized by the various antibodies and illustrates the four isoforms of $\alpha$-syn. Most antibodies recognize a C-terminal epitope in exon 5 in $\alpha$-syn. Consequently, the predominant species that are recognized by assays in which this antibody is used are $\alpha$-syn140 and $\alpha$-syn126 isoforms. Furthermore, assays have been described that specifically recognize the oligomeric and aggregated forms of $\alpha$-syn (see section "Detection of oligomeric \& other modified, potential disease-associated $\alpha$-syn species").

\section{Assays for the detection of total $\alpha$-syn}

Several immunoassays capable of detecting the $\alpha$-syn protein independent of its conformation or aggregation state have been described. These assays will be referred to as 'total' $\alpha$-syn assays, although they do neither detect the full-length protein nor all $\alpha$-syn splice variants [7]. The most widely applied ELISA design/antibody combination for the quantification of total $\alpha$-syn levels is an assay in which $\alpha$-syn is captured by the mouse monoclonal antibody (mAb) 211, and detected by the rabbit polyclonal antibody (pAb) FL-140 [8], which is directed against full length $\alpha$-syn140. Inherent to the use of $\mathrm{mAb} 211$, this assay is expected to detect the splice variants $\alpha$-syn140 and $\alpha$-syn126 (see Figure 2). After its first description [8] several assay modifications have been applied to obtain the best laboratory-specific assay characteristics. Optimization of assay conditions enabled the quantification of $\alpha$-syn in undiluted CSF without prior concentration [9]. Further improvement of assay sensitivity was obtained by incorporation of chemiluminescence instead of colorimetric read-out, thereby lowering the detection limit of the assay to $1 \mathrm{pg} / \mathrm{ml}$ [10]. It should be noted that only part of the studies applying the 211/FL-140 assay demonstrated statistically significant reduced $\alpha$-syn levels in PD CSF as compared with CSF from healthy or neurological controls [8,10-12]. However, other studies did not observe such differences in the CSF [13-16], probably also due to different sample processing, see chapter 'Preanalytical considerations' section below. Mean CSF $\alpha$-syn levels in studies using this 211/ FL-140 assay varied from 18 to $69 \mathrm{ng} / \mathrm{ml}$ for control subjects $[8-14,16,17]$.

In addition to the 211/FL-140 assay, a commercially available ELISA kit has been applied in several studies [18-24]. The $\alpha$-syn isoforms detected by this kit are, however, not specified by the vendor. Mean CSF $\alpha$-syn levels in the several studies using this ELISA kit varied from 0.14 to $1.15 \mathrm{ng} / \mathrm{ml}$ for control subjects. Other assays that have been developed, but applied less frequently, can be divided into three types, assays that are comparable with the 211/FL-140 type, prob- 


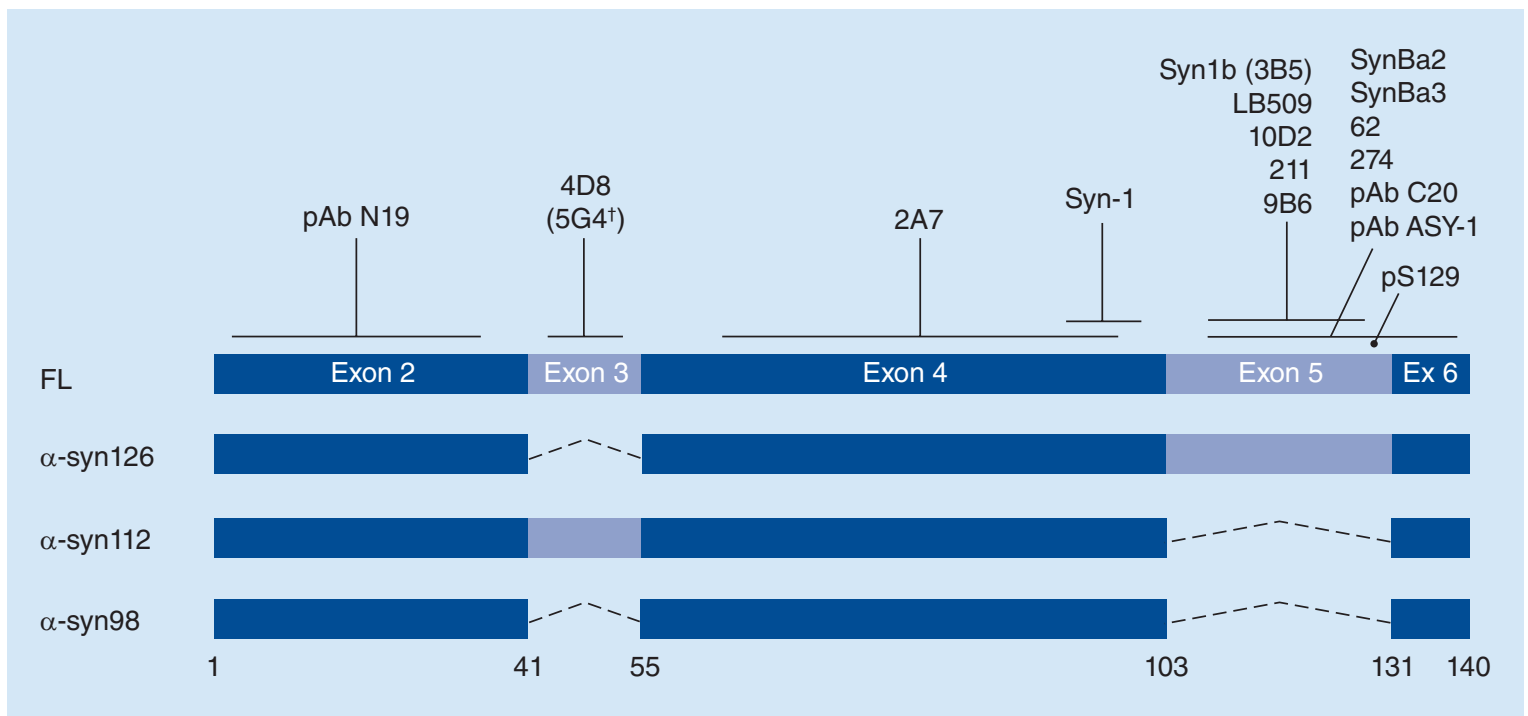

Figure 2. Antibody binding sites of $\alpha$-syn. Schematic representation of $\alpha$-syn isoforms and the binding sites of monoclonal antibodies (mAbs) that have been applied in immunoassays for the quantification of $\alpha$-syn in biological fluids. The start and end of encoding exons are indicated with amino acid numbers. Coding exons that are excised in the splice variants are indicated with a dashed triangle line. The binding sites of three polyclonal antibodies (pAb N19, C20 and ASY-1) are, in addition to mAbs, indicated.

${ }^{+} \mathrm{mAb} 5 \mathrm{G} 4$ preferentially binds aggregated $\alpha$-syn.

$\alpha$-syn126, 112 and 98: $\alpha$-syn splice variants with their respective length in amino acids; FL: full length $\alpha$-syn ( $\alpha$-syn140); pS129: phosphorylated Serine-129.

ably recognizing $\alpha$-syn140 as well as $\alpha$-syn126. These include the following antibody combinations: SynBa2/ SynBa3 [25], Syn-1/C20-HRP [26], 62/274, and Syn1/62 [27], 10D2/FL-140 [28] and FL-140/Syn1b [29]. For the Syn-1/C20-HRP assay detection of other variants cannot be fully excluded. Assays that probably recognize all $\alpha$-syn splice variants, which include the antibody combinations $\mathrm{mSA}-1 / \mathrm{Syn}-1$, the related combination hSA5/Syn-1 [7,30,31] and the antibody combinations 2A7/FL-140 [17], Syn-1/FL-140 [32] and ASY-1/ goat anti- $\alpha$-syn (bead-based Luminex assay) [33]. Mean $\alpha$-syn concentrations in CSF of control subjects quantified by the mSA-1/Syn-1 assay were $1.5-6.0 \mathrm{ng} / \mathrm{ml}$ (assayed in the same lab) [7,34,35], for the 2A7/FL-140 assay $111 \mathrm{ng} / \mathrm{ml}[17]$ and for the ASY-1/goat anti- $\alpha$-syn bead-based assay $0.42-0.47 \mathrm{ng} / \mathrm{ml}$ (assayed in the same lab) $[33,36,37]$. One bead-based assay has been described that likely specifically detects $\alpha$-syn 140 (antibody combination 9B6/4D8) [38]. Interestingly, using this assay much lower mean $\alpha$-syn concentrations of 70 and 111 $\mathrm{pg} / \mathrm{ml}$ were reported for control subjects [38,39]. Finally, besides the above-described alternative immunoassays, the use of a commercially available assay kit (Covance, Inc.) has been described $[34,40,41]$ for which quite consistent mean $\alpha$-syn levels of $1.3-1.5 \mathrm{ng} / \mathrm{ml}$ were measured in control subjects. However, the $\alpha$-syn isoforms detected by this kit are not specified by the vendor.

See Table 1 for a summary of assay characteristics used for measurements of $\alpha$-syn in human CSF.

\section{Detection of oligomeric \& other modified, potential disease-associated $\alpha$-syn species}

Since the utility of the quantification of CSF total $\alpha$-syn is limited, further, more relevant and diseasespecific $\alpha$-syn species move in the focus. One of such species includes soluble aggregated, or oligomeric $\alpha$-syn, a potentially more pathogenic form of $\alpha$-syn [42]. Interestingly, soluble $\alpha$-syn oligomers in brain homogenates of patients with PD and DLB are elevated compared with normal brains [43-45], and the presence of oligomeric $\alpha$-syn in CSF and plasma has been described $[10,46]$. Modified forms, for example, phosphorylated or truncated $\alpha$-syn may be more prone to oligomer formation than unmodified $\alpha$-syn [47-49]. This further suggests that $\alpha$-syn oligomers are associated with PD pathogenesis and proposes that the detection of $\alpha$-syn oligomers in CSF could be a relevant biomarker for PD and related synucleinopathies [50]. This should, however, be approached with caution, as it has been reported that a large part of the endogenous, physiological form of $\alpha$-syn occurs as a folded tetramer [51], not to be mistaken for the diseaseassociated oligomers.

For the quantification of oligomeric $\alpha$-syn in biological fluids, $\alpha$-syn oligomer-specific ELISAs have been established, either with the use of the same monoclonal antibody for both capture and detection or, alternatively, using two different antibodies with overlapping epitopes. The rationale for this is that no signal can 
Table 1. Analysis of total $\alpha$-syn levels in CSF: assays, reference levels and comparison with patient groups.

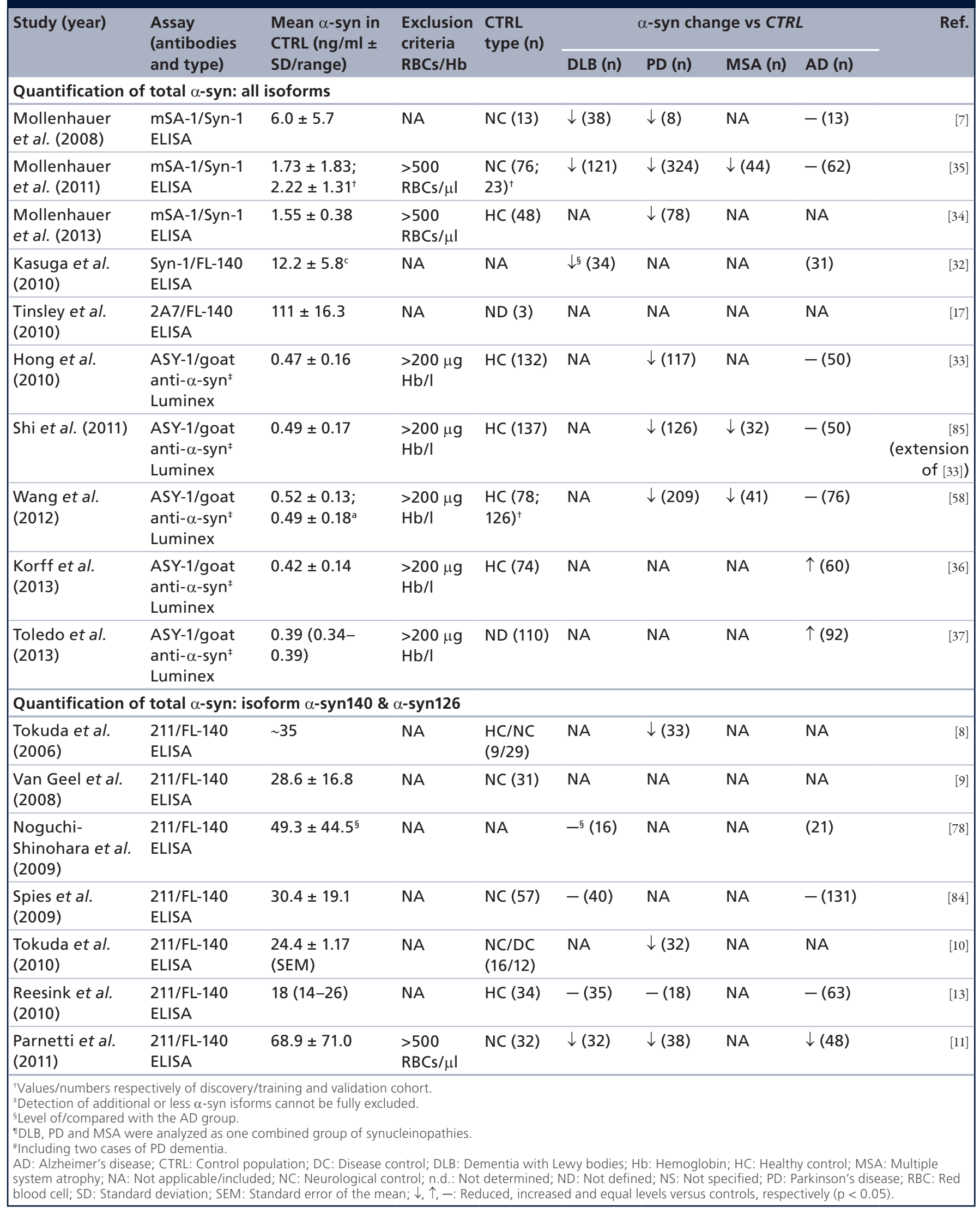


Table 1. Analysis of total $\alpha$-syn levels in CSF: assays, reference levels and comparison with patient groups (cont.).

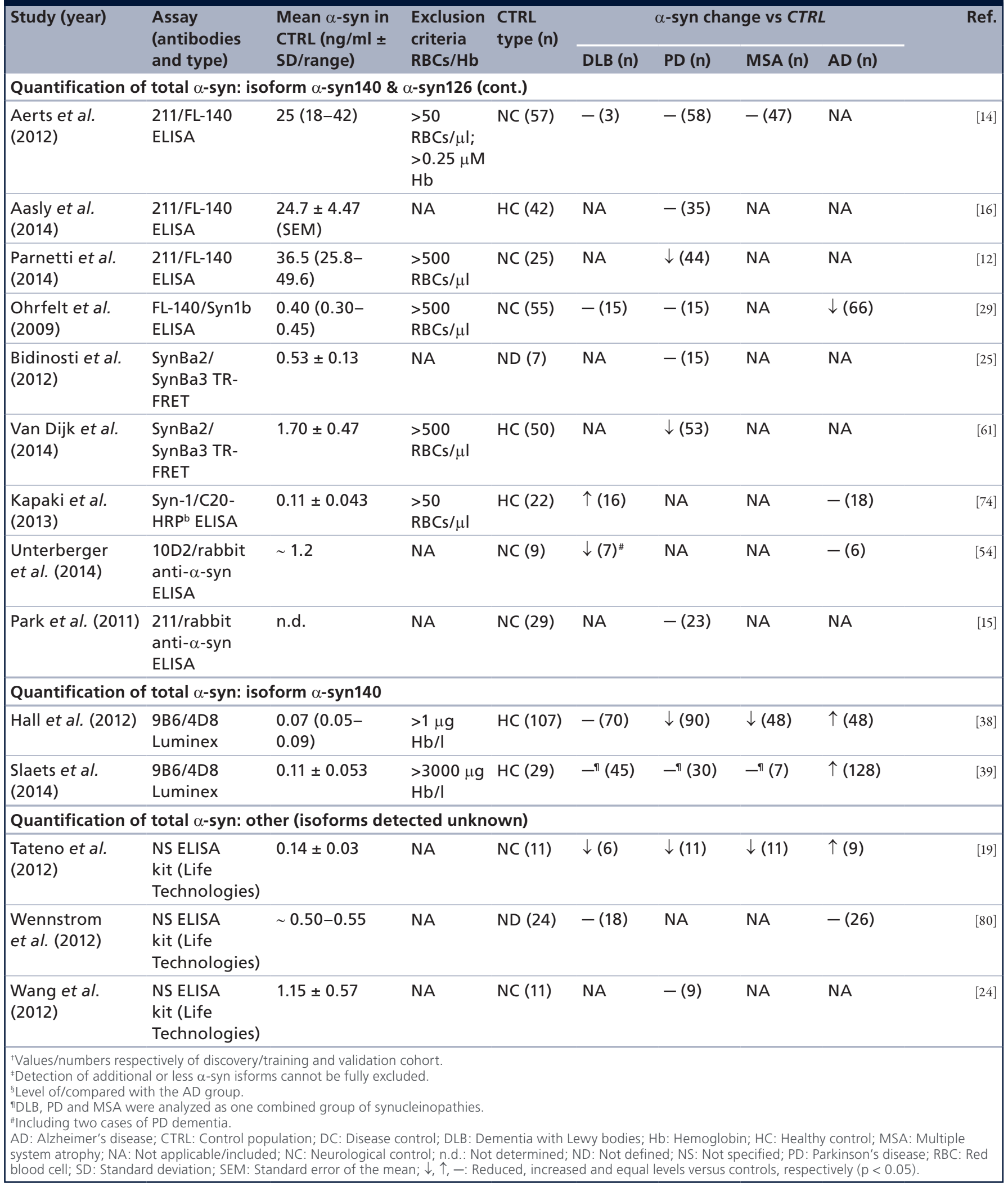


Table 1. Analysis of total $\alpha$-syn levels in CSF: assays, reference levels and comparison with patient groups (cont.).

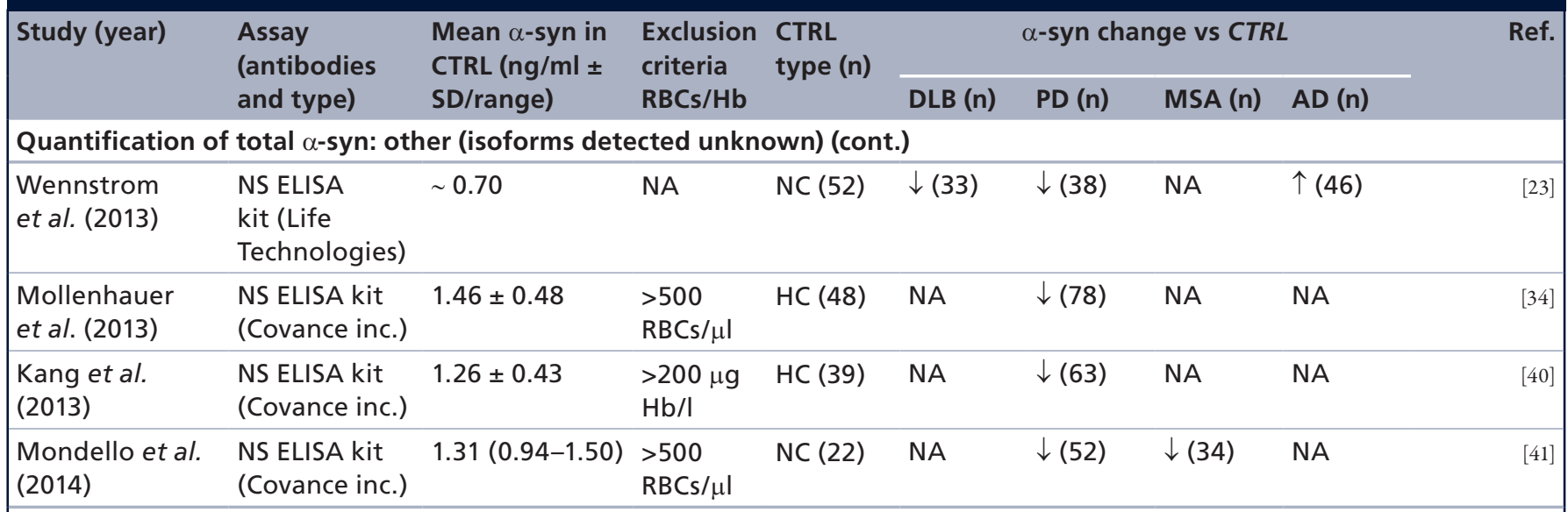

'Values/numbers respectively of discovery/training and validation cohort.

"Detection of additional or less $\alpha$-syn isforms cannot be fully excluded.

¿Level of/compared with the AD group.

"DLB, PD and MSA were analyzed as one combined group of synucleinopathies.

\#Including two cases of PD dementia.

AD: Alzheimer's disease; CTRL: Control population; DC: Disease control; DLB: Dementia with Lewy bodies; Hb: Hemoglobin; HC: Healthy control; MSA: Multiple

system atrophy; NA: Not applicable/included; NC: Neurological control; n.d.: Not determined; ND: Not defined; NS: Not specified; PD: Parkinson's disease; RBC: Red blood cell; SD: Standard deviation; SEM: Standard error of the mean; $\downarrow, \uparrow,-$ : Reduced, increased and equal levels versus controls, respectively $(p<0.05)$.

be detected for monomeric $\alpha$-syn, as the capture mAb binds at the only available antibody binding site on the protein. In contrast, multiple $\mathrm{mAb}$ binding sites are available in the case of oligomeric forms of $\alpha$-syn, thus permitting both capture and detection.

The most frequently used antibody for such oligomeric-ELISA system has been $\mathrm{mAb} 211[10,12,15,16,46,52]$. Optimization of this assay permitted the detection of $\alpha$-syn oligomers in CSF and plasma, showing that $\alpha$-syn oligomers were significantly increased in CSF of PD patients compared with healthy controls $[10,12,15,16]$. In contrast, however, although an initial study observed a significant difference in $\alpha$-syn oligomer levels in plasma of PD patients compared with controls [46], this could not be replicated in other laboratories and studies with larger patient cohorts [15,52].

Recently, other antibodies have also been used in similar immunoassays including $\mathrm{mAb} 62$ [27] and SynBa3 [25]. These assays have not been applied to human biological fluids (62/62-biotin assay) or could not detect $\alpha$-syn oligomers in CSF (SynBa3-FRET assay) likely due to masking of antibody sites by the monomeric forms of $\alpha$-syn. In general, antibodies used for the successful detection of oligomeric a-Syn using this ELISA design recognize epitopes in the C-terminus of $\alpha$-syn. This is probably because the $\mathrm{C}$-terminal part of $\alpha$-syn is accessible and not masked when $\alpha$-syn forms oligomers.

However, there are two important limitations to this assay design: competition of monomers and interference of heterophilic antibodies (as discussed in 'Other factors affecting assay signal output' section). The use of conformation-specific antibodies in immunoassays to detect $\alpha$-syn oligomers may (in part) overcome these problems in that such antibodies do not capture $\alpha$-syn monomers, and an assay design where the same antibody is used for capture and detection is not necessary. However, there is a lack of such antibodies for application in alternative immunoassays. Thus far, two antibodies (FILA-1, 5G4) directed against, or with preferred binding to fibrillar and soluble oligomeric forms of $\alpha$-syn have been published and applied in immunoassays $[28,44,53]$. Recently, in a first feasibility study, antibody $5 \mathrm{G} 4$ has successfully been applied for quantification of $\alpha$-syn in CSF [54]. In this study, $5 \mathrm{G} 4$ was used in combination with antibody $10 \mathrm{D} 2$ in a classic ELISA and in a bead-based Luminex assay, both showing increased (oligomeric) $\alpha$-syn in PD versus control subjects. Therefore, future efforts may be directed toward developing confirmation-specific antibodies for $\alpha$-syn oligomers and to further explore them as biomarker tools for PD.

Other species, for example, post-translationally modified forms of $\alpha$-syn are of interest and potentially more disease-specific, such as $\alpha$-syn phosphorylated at Serine 129 ( $\alpha$-syn-pSer129) [47,55]. $\alpha$-Syn-pSer129 is specifically associated with PD pathology [56] and present in biological fluids. In one study, total $\alpha$-synpSer129 levels were quantified in plasma using an ELISA in which a pAb directed against $\alpha$-syn was combined with a phospho-specific antibody directed against $\alpha$-syn-pSer129 [57]. Total levels of $\alpha$-synpSer129, but neither phosphorylated $\alpha$-syn oligomers nor nonphosphorylated $\alpha$-syn species, tended to be 
higher in plasma of PD patients as compared with controls. In another study, $\alpha$-syn-pSer129 was quantified in CSF from patients with PD, MSA, progressive supranuclear palsy (PSP), AD and control patients in a large cohort study, using an antibody directed against the c-terminus of $\alpha$-syn combined with a phosphospecific anti- $\alpha$-syn-pSer129 antibody in a bead-based Luminex assay. Mean $\alpha$-syn-pSer129 levels in CSF of control subjects were $81.6 \mathrm{pg} / \mathrm{ml}$ [58].

Recently it has been shown that besides phosphorylation changes in nitrosylation of $\alpha$-syn can be measured in serum. An altered profile of $\alpha$-syn tyrosine nitrosylation was detected in patients with early PD relative to controls [59]. Other post-translational modifications of $\alpha$-syn in CSF have been detected and are currently subject to further investigation [60].

An overview of assays used for the quantification of oligomeric and phosphorylated $\alpha$-syn species in CSF is given in Table 2.

\section{Other assay platforms}

The number of studies that have quantified CSF levels of $\alpha$-syn with other, more innovative techniques than ELISA is increasing:

- In several studies [33,36-39,58], antibodies ASY-1 or 9B6 were coupled with beads (Luminex assay) to analyze the CSF levels of total $\alpha$-syn. In addition, in one study antibody $5 \mathrm{G} 4$ was coupled to beads to analyze the levels of oligomeric $\alpha$-syn in CSF [54]. The advantage of this type of assay as compared with the conventional ELISA is the possibility of multiplexing and the potentially lower coefficient of variation due to multiple readings per sample. In these studies using bead-based assays, total levels of $\alpha$-syn were, as far as assessed, generally decreased in PD patients compared with healthy controls, but in one study only after eliminating samples with blood contamination [33]. Furthermore, in this latter study, there was no significant difference between levels of $\alpha$-syn in the different stages of PD;

- $\alpha$-Syn has been quantified using an electrochemiluminescence assay (hSA5/Syn-1 assay) [30,31], which has also the advantage of a multiplexing option;

- A one-step assay has been developed [25], using the antibodies SynBa2 and SynBa3, for in-solution quantification of total and oligomeric $\alpha$-syn by time-resolved Förster's resonance energy transfer (TR-FRET). The LOD of the total $\alpha$-syn assay was comparable to existing ELISA techniques; however, the TR-FRET assay is more suitable for highthroughput screening. Furthermore, using this tech- nique the levels of CSF total $\alpha$-syn were significantly lower in PD compared with healthy controls [61].

So far, all reported measurements of $\alpha$-syn are based on immunoassay platforms, whereas other quantification systems based on MS are in development [60].

\section{Quantification of $\alpha$-syn in peripheral biological fluids}

The optimal biomarker for a specific disease reflects aspects proximal to the disease process. Although CSF seems optimal for neurological diseases due to its proximity to the CNS [62], the relative invasiveness of lumbar punctures is still a major drawback. And therefore, to rely on CSF for biomarker development is not optimal.

For PD, however, this may not even be necessary in the future: the distribution of $\alpha$-syn pathology points toward PD as a systemic disease with the affection of the peripheral nervous system and organs [63]. Therefore the chances to detect a peripheral marker in more easily accessible biological fluids than CSF may be higher than, for example, in AD. Since it is known that red blood cells (RBCs) are a major source of $\alpha$-syn, detection of $\alpha$-syn in different blood components has been pursued as a biomarker for PD [64,65], which, however, has led to discrepant findings in several studies (see Table 3 for an overview). The wide range of $\alpha$-syn concentrations in peripheral blood compartments has been determined in comparison to CSF: cell-free CSF $(1.57+0.6 \mathrm{ng} / \mathrm{ml})$, serum $(12.69+10.3$ $\mathrm{ng} / \mathrm{ml})$, plasma $(59.54+35.1 \mathrm{ng} / \mathrm{ml})$ and whole blood lysates $(5002+3828 \mathrm{ng} / \mathrm{ml})[4,65]$.

These differences may be attributed to different sample processing and yet to be identified confounding factors, or, more importantly because of the yet unknown role of blood-derived $\alpha$-syn in the pathophysiology of PD. CSF $\alpha$-syn predominantly derives from neurons of the CNS [66]. Whether $\alpha$-syn quantified in peripheral blood components is still a proximal marker for PD needs to be shown.

Some of the above-described assay designs have been applied to plasma and serum analysis. Using the 211/ FL-140 assay design, it has been described that the addition of $1 \%(\mathrm{v} / \mathrm{v})$ Tween-20 to plasma, in combination with the use of alkaline phosphatase (AP) instead of HRP as enzyme for substrate conversion, improves quantification of $\alpha$-syn in plasma [17]. The rationale behind this approach was reduction of nonspecific binding of proteins and lipids that reduced antibodyantigen interaction, and to avoid the confounding effect of endogenous peroxidases in blood components. $\alpha$-syn was measurable in plasma in this study at a mean concentration of $29 \mathrm{ng} / \mathrm{ml}$. Two other stud- 
Table 2. Analysis of oligomeric and phosphorylated $\alpha$-syn species in CSF: assays, reference levels and comparison with patient groups.

\begin{tabular}{|c|c|c|c|c|c|c|c|c|c|}
\hline \multirow[t]{2}{*}{ Study (year) } & \multirow{2}{*}{$\begin{array}{l}\text { Assay } \\
\text { (antibodies } \\
\text { and type) }\end{array}$} & \multirow{2}{*}{$\begin{array}{l}\text { Mean } \alpha \text {-syn } \\
\text { in } \mathrm{CTRL}^{+}\end{array}$} & \multirow{2}{*}{$\begin{array}{l}\text { Exclusion } \\
\text { criteria } \\
\text { RBCs/Hb }\end{array}$} & \multirow{2}{*}{$\begin{array}{l}\text { CTRL type } \\
\text { (n) }\end{array}$} & \multicolumn{4}{|c|}{$\alpha$-syn change vs $C T R L$} & \multirow[t]{2}{*}{ Ref. } \\
\hline & & & & & DLB (n) & PD (n) & MSA (n) & $A D(n)$ & \\
\hline \multicolumn{10}{|c|}{ Quantification of oligomeric $\alpha$-syn } \\
\hline Tokuda et al. (2010) & $\begin{array}{l}\text { 211/211-biotin } \\
\text { ELISA }\end{array}$ & $\begin{array}{l}5.32 \pm 0.85 \\
(\mathrm{NC} ; \pm \mathrm{SEM})\end{array}$ & NA & $\begin{array}{l}\text { NC/DC; ND } \\
(16 / 12 ; 43)^{\pi}\end{array}$ & NA & $\begin{array}{l}\uparrow \neq, \S ; \uparrow \neq \\
(32 ; 25)^{\natural}\end{array}$ & NA & $\begin{array}{l}\text { NA; }--^{\ddagger, \S} \\
(N A ; 35)^{\uparrow}\end{array}$ & [10] \\
\hline Park et al. (2011) & $\begin{array}{l}\text { 211/211-biotin } \\
\text { ELISA }\end{array}$ & n.d. & NA & NC (29) & NA & $\uparrow \neq(23)$ & NA & NA & {$[15]$} \\
\hline Aasly et al. (2014) & $\begin{array}{l}\text { 211/211-biotin } \\
\text { ELISA }\end{array}$ & $\begin{array}{l}40.97 \pm 21.62 \\
( \pm \text { SEM })\end{array}$ & NA & $\mathrm{HC}(42)$ & NA & $\uparrow \neq, \S(35)$ & NA & NA & {$[16]$} \\
\hline $\begin{array}{l}\text { Parnetti et al. } \\
\text { (2014) }\end{array}$ & $\begin{array}{l}\text { 211/211-biotin } \\
\text { ELISA }\end{array}$ & $\begin{array}{l}0.021(0.014- \\
0.043)\end{array}$ & $\begin{array}{l}>500 \mathrm{RBCs} / \\
\mu \mathrm{l}\end{array}$ & $N C(25)$ & NA & $\uparrow \neq, \S(44)$ & NA & NA & [12] \\
\hline $\begin{array}{l}\text { Unterberger et al. } \\
\text { (2014) }\end{array}$ & $\begin{array}{l}5 G 4 / 10 D 2 \\
\text { ELISA and } \\
\text { Luminex }\end{array}$ & $\begin{array}{l}<0.01 \mathrm{ng} \\
\text { oligomers/ml }\end{array}$ & NA & $\mathrm{NC}(9)$ & $\uparrow_{\S}(7)^{\#}$ & NA & NA & $-(6)$ & [54] \\
\hline Wang et al. (2012) & $\begin{array}{l}\text { ASY-1/pSer129 } \\
\text { Luminex }\end{array}$ & $\begin{array}{l}81.6 \pm 20.4 \\
73.0 \pm 17.2 \\
\mathrm{pg} / \mathrm{ml}^{\uparrow}\end{array}$ & $\begin{array}{l}>200 \mu \mathrm{g} \\
\mathrm{Hb} / \mathrm{l}\end{array}$ & $\begin{array}{l}\mathrm{HC}(78 ; \\
126)^{\pi}\end{array}$ & NA & 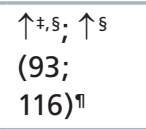 & $\begin{array}{l}\uparrow \S ;-\neq, \S \\
(16 ; 25)^{\uparrow}\end{array}$ & $\begin{array}{l}-\neq, \S ;-一^{\neq, \S} \\
(26 ; 50)^{\natural}\end{array}$ & [58] \\
\hline \multicolumn{10}{|c|}{$\begin{array}{l}\text { 'Levels indicated as absolute concentrations or ratio versus total } \alpha \text {-syn } \pm \text { standard deviation or range. } \\
\text { "Change applicable for level of oligomeric (or phosphorylated) } \alpha \text {-syn. } \\
{ }^{\S} \text { Change applicable for } \alpha \text {-syn ratio (oligomeric or phosphorylated } \alpha \text {-syn vs total } \alpha \text {-syn). } \\
\text { "Values/numbers respectively of discovery/training and validation cohort. } \\
\text { "Including two cases of PD dementia. } \\
\text { AD: Alzheimer's disease: CTRL: Control population; DC: Disease control; DLB: Dementia with Lewy bodies; Hb: Hemoglobin; HC: Healthy control; MSA: Multiple } \\
\text { system atrophy; NA: Not applicable/included; NC: Neurological control; } n \text {.d.: Not determined; ND: Not defined; PD: Parkinson's disease; RBC: Red blood cell; } \\
\text { SEM: Standard error of the mean; } \uparrow \text {,-: Increased and equal levels versus controls, respectively ( } p<0.05 \text { ). }\end{array}$} \\
\hline
\end{tabular}

ies also quantified $\alpha$-syn in plasma using this antibody combination, showing either no significant difference between PD and neurological controls [15], or reduced levels in PD as compared with healthy controls [52]. The latter study did use HRP as enzyme in the assay and measured a much higher median plasma $\alpha$-syn concentration of $617 \mathrm{ng} / \mathrm{ml}$ in control subjects. Comparable assay designs, in other words, detecting the same $\alpha$-syn isoforms as the 211/FL-140 assay, have been applied to serum and plasma analysis $[18,22,27,67]$, showing mean $\alpha$-syn levels in control subjects ranging from 2 to 89 $\mathrm{ng} / \mathrm{ml}$. $\alpha$-Syn levels in plasma of PD patients were either increased [18] or unchanged [67]. Finally, using assay designs detecting all $\alpha$-syn isoforms, mean $\alpha$-syn serum/plasma levels of 18 to $132 \mathrm{ng} / \mathrm{ml}$ were recorded in control subjects $[17,34,68]$, with similar levels in serum of PD versus control patients [68]. Thus the role and utility as biomarker of $\alpha$-syn in peripheral blood compartments is still unclear.

$\alpha$-syn has also been quantified in saliva [69] after the presence of $\alpha$-syn in salivary glands has been shown postmortem [1]. Salivary levels of $\alpha$-syn showed a nonsignificant toward lower levels in patients with PD compared with controls in this first explorative study [69]. Due to the early involvement of the GI tract in $\mathrm{PD}$, different tissue biopsies (from the colon and stomach) have been analyzed for $\alpha$-syn. Besides technical problems with the depth of biopsy the invasiveness of such a biopsy needs to be opposed to a lumbar puncture. See Table 3 for an overview of assays used for the quantification, and performance in differential diagnosis, of various $\alpha$-syn species in biological fluids other than CSF.

\section{Other factors affecting assay signal output}

Besides the use of different antibodies with different affinities, recognizing different $\alpha$-syn species (see 'Preanalytical considerations' section above), other factors can be recognized that affect the assay signal and cause variation in biomarker measurements, irrespective of the used assay design. These factors include: variation in standard peptides: there is no standardization of the standard peptides used in the various assays, while this may be an important factor in varying assay outcomes $[4,25]$. Especially the controlled generation of oligomeric forms of $\alpha$-syn in size and conformation has proven to be difficult, as can be deduced from the results of studies included in Table 2. Most of these studies did not use standards but instead used the assay signal (in light units) of oligomers in a ratio 


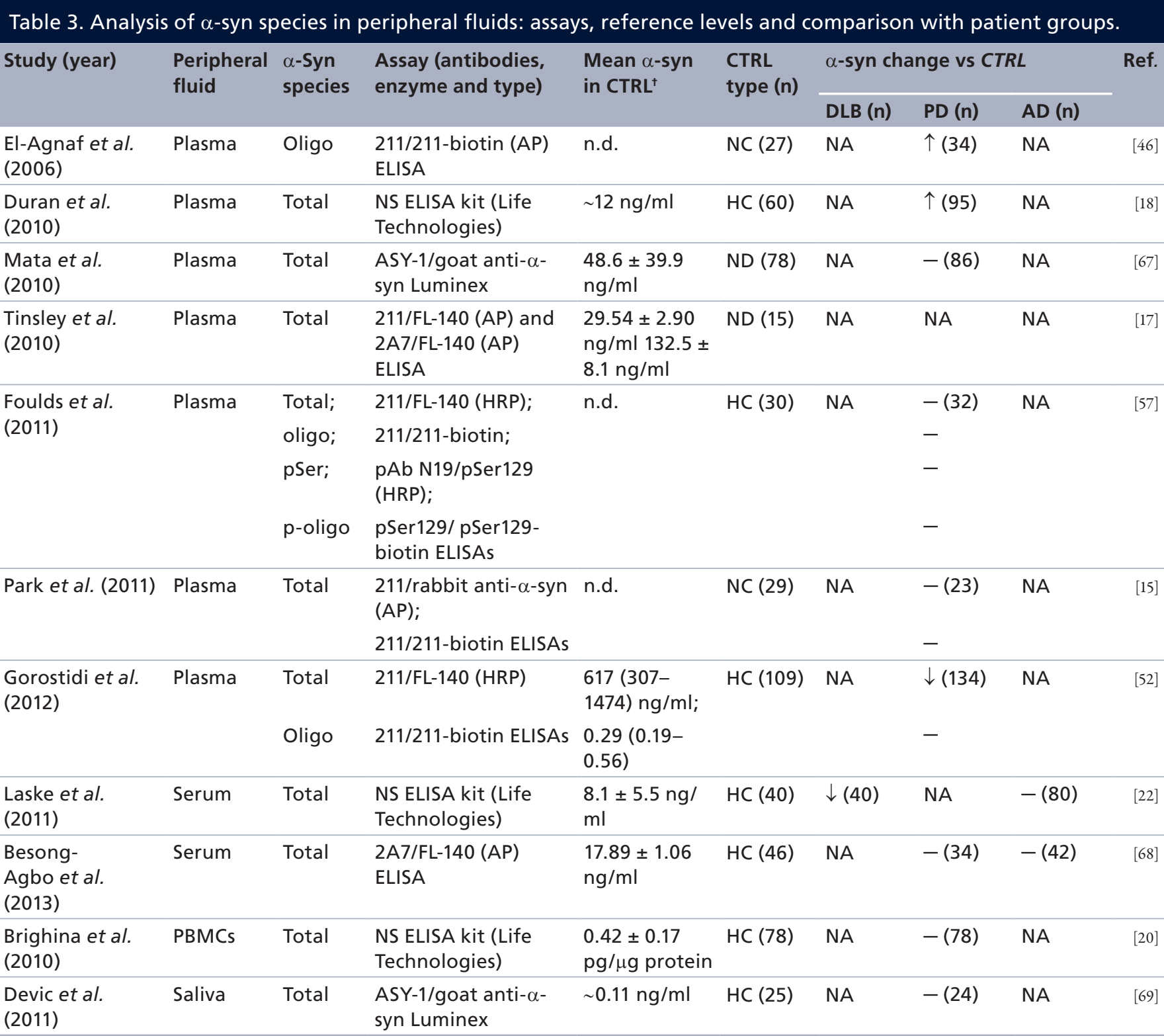

${ }^{+}$Levels indicated as absolute concentration (total $\alpha$-syn) or $\alpha$-syn ratio (oligomeric $\alpha$-syn; ratio vs total $\alpha$-syn) \pm standard deviation or range.

AD: Alzheimer's disease; AP: Alkaline phosphatase; CTRL: Control population; DLB: Dementia with Lewy bodies; HC: Healthy control; HRP: Horseradish peroxidase; NA: Not applicable/included; NC: Neurological control; n.d.: Not determined; ND: Not defined; NS: Not specified; PBMC: Peripheral blood mononuclear cell; PD: Parkinson's disease; oligo, pSer, p-oligo: Respectively oligomeric, phosphorylated and phosphorylated-oligomeric $\alpha$-syn; $\downarrow$, $\uparrow$, - : Reduced, increased and equal levels versus controls, respectively $(\mathrm{p}<0.05)$.

versus the total $\alpha$-syn signal as output. Interference of heterophilic antibodies: heterophilic antibodies are antibodies that are found in patients and have affinity for animal antibodies. These antibodies are very common, and are present in up to $40 \%$ of the population. Although, such antibodies recognize a broad range of antigens, affinity for the Fc-region especially of mouse antibodies of the IgG1 subtype (most often used in ELISAs) are over-represented and show generally higher affinity than heterophilic antibodies directed against other antigens [70]. Such heterophilic antibodies in the CSF (and, even more importantly, in blood components) may cross-link capture and detection antibodies in the absence of antigen, resulting in false-positive results [71,72]. This is especially a problem when the capture and detection antibodies are from the same species, for example, in the $\alpha$-syn oligomer ELISA design where the same antibody is used for capturing and detecting the antigen. Obviously, reduction of the chance of this type of interference to occur is the use of antibodies from different species. Other methods may include the use of heterophilic antibody blockers, sample depletion for heterophilic antibodies prior to analysis or usage of antibody fragments that do 
not contain the Fc-portion [70]. Competition of monomers: the $\alpha$-syn oligomer assay design that uses the same antibody for capture and detection, enables the coating $\mathrm{mAbs}$ to capture all forms of $\alpha$-syn, including monomers. The monomers, especially when excessively present, compete with the multimeric forms of $\alpha$-syn for binding to the capture antibodies and thereby reduce the detection of oligomeric species [25]. Interference of endogenous peroxidases: because blood components can contain endogenous peroxidases, this can in combination with the use of HRP as enzyme to convert the substrate in the assay increase background signals. This may be overcome by the use of an alternative enzyme, for example, AP. The enzymes used in the various studies that investigated $\alpha$-syn levels in peripheral fluids are indicated in Table 3.

\section{Preanalytical considerations}

It is well known from biomarker studies in the $\mathrm{AD}$ field that preanalytical factors can confound the results of analysis.

First of all, blood contamination due to traumatic lumbar puncture, as preanalytical factor, has been recognized as a serious problem for $\alpha$-syn quantitation in CSF. The levels of $\alpha$-syn in serum and plasma are up to 10,000 -fold higher than in CSF as given above $[4,73]$, probably due to the many blood cells (e.g., erythrocytes are a major source of $\alpha$-syn) [64,74]. A positive correlation has been described between $\alpha$-syn levels and the number of RBCs in CSF unless there were fewer than $50 \mathrm{RBCs}$ present [74].

With regard to the type of the needle used for lumbar puncture, it has been shown that the use of atraumatic needles is associated with a lower risk of complications, such as postlumbar puncture headache and traumatic taps (as per the count of RBCs per milliliter in the first sample of CSF), as opposed to traumatic needles $[75,76]$.

Recent recommendations on preanalytical standard operation procedures (SOPs) for PD CSF biomarkers have therefore recommended less than 50 RBCs per microliter for CSF samples to be suitable for $\alpha$-syn determination [77]. In addition, hemoglobin levels may be determined as indicator for blood contamination, which may be especially useful in samples, which have not been optimally processed with centrifugation before freezing [33]. For optimal sample processing (tube selection, centrifugation steps, storage conditions, freeze and thaw steps, etc.) we refer to a recent publication that includes a literature review [77].

Demographic factors like sex and age have been investigated in some studies: most studies reported a decrease in $\alpha$-syn levels with age $[7,8,29,78]$, except for two studies that showed no change [9] or increased $\alpha$-syn levels [33]. The age dependence became weaker when patients with PD were considered. None of the studies mentioned above reported gender-related differences in the CSF levels of $\alpha$-syn. Expression of dopamine receptors in the choroid plexus could alter CSF homeostasis and hence influence $\alpha$-syn levels in patients treated with Levodopa [79]. However, in two studies with advanced and medicated PD patients no correlation with CSF $\alpha$-syn and the Levodopa dosage was found $[33,35]$.

Diurnal variation in CSF concentration has been reported for several proteins [80-82] and is relevant as for the time of the day the lumbar puncture is performed in clinical routine. It was observed, however that CSF $\alpha$-syn levels were not affected by diurnal fluctuations over a 33-h period [83]. A rostro-caudal concentration gradient was excluded for CSF $\alpha$-syn in two studies $[33,66]$. The influence of food intake or glucose levels on $\alpha$-syn levels has not been investigated systematically.

\section{Diagnostic performance of CSF $\alpha$-synuclein as biomarker for $\alpha$-synucleinopathies Differential diagnosis of Parkinson's disease}

A number of studies have evaluated the potential value of CSF $\alpha$-syn as a diagnostic biomarker for $\alpha$-synucleinopathies, but results were conflicting (see Table 1). Some studies found decreased CSF total $\alpha$-syn levels in patients with an $\alpha$-synucleinopathy as compared with controls or AD patients [7,8,10-12,19,23,32-35,39$41,61]$. In three of these studies it was shown that $\alpha$-syn levels in CSF were decreased in $\alpha$-synucleinopathies (PD, DLB and/or MSA) as compared with tauopathies (PSP and/or corticobasal syndrome (CBS)) [35,38,41], while in another study [11] $\alpha$-syn CSF levels were significantly lower in DLB and frontotemporal dementia (FTD) patients compared with PD patients.

In contrast to these findings, however, other studies reported nonsignificant differences between different diagnostic groups $[13-16,24,78,84]$. For example, $P D$ and PSP/CBS could not be differentiated using CSF $\alpha$-syn levels in one study [14].

One diagnostic study has been performed with CSF $\alpha$-syn-pSer129 (see Table 2). This biomarker was quantified in CSF of PD, MSA, PSP, AD and control patients in a large cohort study. $\alpha$-Syn-pSer129 levels were significantly higher in CSF of PD patients compared with MSA, PSP and control subjects in a training cohort and findings were confirmed in a validation cohort. Moreover, the diagnostic performance was increased by combining phosphorylated $\alpha$-syn with total $\alpha$-syn levels [58].

\section{Differential diagnosis of dementing disorders}

The quantification of CSF $\alpha$-syn may also be of diagnostic value to identify DLB as a cause of dementia 
as opposed to, for example, AD. CSF $\alpha$-syn could, however, not differentiate between DLB and AD in most studies $[11,13,54,78,80,84]$, although in one of these studies a decrease in $\alpha$-syn was observed in female patients with DLB versus those with $\mathrm{AD}$ [80]. In contrast, a few other studies reported significantly lower $\alpha$-syn levels in CSF $[7,32,39]$ and serum [22] in DLB/ $\alpha$ synucleinopathies compared with $\mathrm{AD} /$ other dementias. For instance, recently in a large study comprising patients with AD, DLB, PD, PD with dementia (PDD) and MSA of whom a subset of 49/233 patients had autopsy-confirmed diagnoses significantly increased $\alpha$-syn levels were found in AD patients as compared with DLB/ $\alpha$-synucleinopathies [39]. In contrast, another study showed significantly increased $\alpha$-syn levels in CSF of DLB patients compared with AD [74]. In this study they strictly adhered to recent recommendations [77] on controlling for confounding factors. In addition, one recent study showed increased CSF $\alpha$-syn levels in AD patients and patients with mild cognitive impairment (MCI), as compared with controls, with modest sensitivity and specificity [36]. In this study, $\alpha$-syn CSF levels in AD were also higher than in MCI, but this was not statistically significant. Interestingly, $\alpha$-syn CSF levels were in general negatively correlated with Mini Mental Status Examination score.

\section{Combination of the quantification of $\alpha$-syn together with amyloid- $\beta 42$ \& tau proteins in differential diagnosis}

The number of studies analyzing the biomarker potential $\alpha$-syn for dementia in combination with AD biomarkers is fast increasing. Combining $\alpha$-syn with AD biomarkers, such as A $\beta 42$ as well as total and phosphorylated tau proteins (t-tau; p-tau181P) may help to differentiate PD from other neurological disorders and might help to improve the differentiation between PDD/DLB and AD or other neurodegenerative disorders. One study showed that the ratio of t-tau/ $\alpha$-syn (and to a slightly lesser extent the p-tau/ $\alpha$-syn ratio) in CSF could contribute to the differentiation of PD from DLB, AD and FTD with a sensitivity of $89 \%$, and specificity of $61 \%$ [11]. In another study, $\alpha$-syn in combination with the t-tau/p-tau ratio could differentiate PD from MSA (sensitivity 90\%, specificity 71\%) [85]. In yet another study the combination of $\alpha$-syn, t-tau and age could differentiate $\alpha$-synuclein-related disorders (namely, DLB, PD and MSA) from non- $\alpha$ synuclein-related disorders (namely, normal pressure hydrocephalus [NPH], PSP and other neurodegenerative disease) [35]. A diagnostic algorithm using $\alpha$-syn and p-tau181P discriminated neuropathologically confirmed DLB from AD patients resulting in sensitivity and specificity values of 85 and $81 \%$, respectively [39].
Finally, one study showed that in multivariate analysis combining the classical AD biomarkers ( $\mathrm{t}$-tau protein and $A \beta 42$ ) with $\alpha$-syn contributed the most to the differentiation of AD from DLB and PDD [38]. Together these studies show the potential of combining $\alpha$-syn with other biomarkers like $A \beta 42$, $t$-tau and $p$-tau181P to improve differential diagnosis of PD and related diseases. Next to A $\beta 42$, t-tau and p-tau181P, also other potential candidates may be found for this purpose, for instance NFL, which showed promising results as biomarker for atypical PD $[38,86,87]$.

\section{Diagnostic performance of $\alpha$-syn oligomers}

The observation that $\alpha$-syn induces fibrillization of tau, and that co-incubation of tau and $\alpha$-syn synergistically promotes fibrillization of both proteins [88] is of particular relevance for studies investigating these two molecules as putative CSF diagnostic/prognostic biomarkers in different PD clinical phenotypes.

Only few studies have analyzed oligomeric forms of $\alpha$-syn in differential diagnosis (see Table 2). Although several studies showed increased levels of $\alpha$-syn oligomers in PD CSF as compared with healthy or neurological controls $[10,12,15,16,46]$, we identified only one study in which $\alpha$-syn oligomer levels in CSF of PD versus other disease groups were compared. In this study, $\alpha$-syn oligomer levels, especially the ratio of oligomers to total $\alpha$-syn levels, were significantly increased in PD patients in comparison to PSP and AD patients [10].

\section{Early diagnosis of Parkinson's disease}

The number of studies that assessed the diagnostic value of CSF $\alpha$-syn in early stages of disease is also limited, but results indicate a decrease of CSF $\alpha$-syn in early symptomatic PD patients as in more advanced disease stages (as summarized above). One singlecenter study showed significantly decreased $\alpha$-syn CSF levels in untreated early PD patients compared with healthy controls [34]; this observation was recently confirmed in a multicenter setting [40]. Another study showed that $\alpha$-syn oligomers in CSF of early PD patients (within 24 months after onset) were higher than those of healthy or disease controls [10].

\section{$\alpha$-Syn biomarker properties for asymptomatic mutation carriers \& relation to disease severity} In a study that examined asymptomatic LRRK2 mutation carriers, CSF $\alpha$-syn levels did not correlate with dopaminergic neuron loss in the striatum as observed by PET imaging [89]. The results of this study suggest that CSF $\alpha$-syn does not predict the development of clinical symptoms in the presymptomatic phases of PD or other $\alpha$-syn-related diseases linked to LRRK2 mutations. The results in the symptomatic patients have 
been contradictory. In one study there was no association between the disease severity measured by Hoehn and Yahr (H\&Y) scale and CSF $\alpha$-syn [33], whereas in another study a significant association between these parameters and $\alpha$-syn was observed [8], and in yet another study such an association was only evident for sporadic PD, but not for symptomatic LRRK2 carriers [16]. Furthermore, phosphorylated $\alpha$-syn was shown to be associated with UPDRS but not with H\&Y scale [58]. The limitation of these studies is the small sample size. Studies addressing biomarkers in other asymptomatic mutation carriers, subjects with rapid eye movement (REM) sleep behavior disorder and/or hyposmic subjects, all at risk to develop PD and results from ongoing longitudinal studies are under way.

\section{Conclusion}

In summary, the studies reviewed above reveal that there are large variations in the absolute levels of $\alpha$-syn in CSF and serum, even when the same types of $\alpha$-syn isoforms are detected. Differences in values are therefore likely to be related to different analytical procedures, which imply a strong need for standardization of procedures.

CSF $\alpha$-syn might have clinical diagnostic potential in movement disorders for differentiating $\alpha$-synucleinrelated disorders (PD/DLB/MSA), where decreased CSF $\alpha$-syn levels are observed, from not $\alpha$-syn-related disorders (e.g., PSP and NPH), where normal CSF $\alpha$-syn levels are observed. Interestingly, these abnormal levels are already found in early stages of the disease and thus have potential for early diagnosis. Large, systematic studies will be still needed, however, to clarify whether $\alpha$-syn alone or in combination with other biomarkers such as A $\beta 42$, t-tau, $\mathrm{p}$-tau181P and possibly NFL can improve the differential diagnosis between neurodegenerative disorders and to improve the early diagnosis of PD. Longitudinal studies have been initiated [90,91] and will further shed light if our current biomarkers can reflect the continuing neurodegeneration process.

A limitation of most biomarker studies is that they rely on clinical diagnoses, which base on insufficient clinical criteria with an accuracy of only 80-90\% compared with neuropathological diagnoses, even when the diagnoses are made by experts in movement disorders [2]. Confirmation in independent study populations that preferably contain autopsy-confirmed patients is needed as are diagnoses made on combinations of different CSF markers and the combination of other marker modalities.

In conclusion, different $\alpha$-syn species are promising candidates as biomarkers of synuclein-related diseases; however, further research is needed to confirm their diagnostic utility.

\section{Future perspectives for $\alpha$-syn quantification as a biomarker in clinical routine}

The studies reviewed here have been performed by using several different methods exploiting different antibodies to measure $\alpha$-syn and these studies have also measured different $\alpha$-syn species, in other words, total $\alpha$-syn, phosphorylated $\alpha$-syn or oligomeric $\alpha$-syn. Before any definite conclusions about the usefulness of the measurement of $\alpha$-syn species in CSF or other body fluids to aid in the diagnosis of neurodegenerative disease can be made, there should be large-scale validation studies using standardized assays and procedures. Preferably, these studies should include large prospective cohorts with patients with different $\alpha$-synucleinrelated and other neurodegenerative diseases with detailed information on clinical phenotype as well as medication during a follow-up. Furthermore, considering the prevalence of overlapping neuropathology in many patients $[92,93]$, patients with neuropathological confirmation of the disease would be of tremendous importance. A large cohort would also enable investigation of possible preanalytical and clinical confounding factors affecting CSF $\alpha$-syn as discussed earlier. For example, as $\alpha$-syn is a soluble intracellular protein, future studies should assess the possible factors that may affect the release of $\alpha$-syn from the synapse into the extracellular space.

Regardless of whether CSF $\alpha$-syn levels alone are sufficiently accurate to support the clinical diagnosis, these levels may however be useful as part of a panel of biomarkers reflecting different pathways involved in the disease $[11,38,94]$. This approach would allow for better and timelier characterization of clinical PD subtypes, with special emphasis on different clinical phenotypes and prognoses.

Future studies are needed to ascertain whether more accessible peripheral fluids can be used to measure biomarker levels more efficiently than current CSF tests.

\section{Financial \& competing interests disclosure}

This is an EU Joint Programme - Neurodegenerative Disease Research (JPND) project. The project is supported through the following funding organizations under the aegis of JPND - www.jpnd.eu: Denmark (Innovation Fund Denmark); Finland (Academy of Finland, Research Council for Health); Germany (BMBF); Italy (Finanziamento Ministero Salute); The Netherlands: (ZonMw); S Engelborghs is supported by the University of Antwerp Research Fund and the Alzheimer Research Foundation (SAO-FRA). This research has also been co-financed by ERDF (European Regional Development Fund) and Greek national funds through the Operational Program 'Competitiveness and Entrepreneurship' of the NSRF (National Strategic Reference Framework); reek national funds through the Operational Program 'Competitiveness and En- 
trepreneurship' of the NSRF (National Strategic Reference Framework). S Engelborghs was/is consultant for Innogenetics/Fujirebio Europe and Roche diagnostics. I Rektorova is supported by the project 'CEITEC-Central European Institute of Technology' (CZ.1.05/1.100.02.0068) from the European Regional Development Fund. E Vanmechelen is a co-founder of ADx NeuroSciences. MM Verbeek served on an advisory board for Roche. B Mollenhauer has received independent research grants from TEVA-Pharma, Desitin, Boehringer Ingelheim, GE Healthcare and honoraria for consultancy from Bayer Schering Pharma AG, Roche, AbbVie, TEVA-Pharma, for presentations from GlaxoSmithKline, Orion Pharma, TEVA-Pharma and travel costs from TEVA-Pharma. B Mollenhauer is member of the executive steering committee of the Parkinson Progression Marker Initiative of the Michael
J. Fox Foundation for Parkinson's Research and has received grants from the BMBF, EU, Deutsche Parkinson Vereinigung, Michael J. Fox Foundation for Parkinson's Research, Stifterverband für die deutsche Wissenschaft, and has scientific collaborations with Roche, Ely Lilly, BioLegend and Biogen Idec. B Mollenhauer is listed as co-inventors in a patent application to the US Patent Office related to the quantification of $\alpha$-synuclein in biological fluids for the purpose of improved diagnosis. The authors have no other relevant affiliations or financial involvement with any organization or entity with a financial interest in or financial conflict with the subject matter or materials discussed in the manuscript apart from those disclosed.

No writing assistance was utilized in the production of this manuscript.

Executive summary

- $\alpha$-syn can be quantitated in cerebrospinal fluid and plasma/serum.

- Large variations in the measured levels of $\alpha$-synuclein are seen across different assays.

- The differences are probably due to differences in both preanalytical and analytical procedures.

- Levels of $\alpha$-synuclein may be useful to support the early diagnosis of Parkinson's disease.

- Future efforts should concentrate on harmonization of preanalytical and analytical procedures as well as the analysis of larger cohorts of patient samples.

\section{References}

1 Del Tredici K, Hawkes CH, Ghebremedhin E, Braak H. Lewy pathology in the submandibular gland of individuals with incidental Lewy body disease and sporadic Parkinson's disease. Acta Neuropathol. 119(6), 703-713 (2010).

2 Hughes AJ, Daniel SE, Kilford L, Lees AJ. Accuracy of clinical diagnosis of idiopathic Parkinson's disease: a clinico-pathological study of 100 cases. J. Neurol. Neurosurg. Psychiatry 55(3), 181-184 (1992).

3 El-Agnaf OM, Salem SA, Paleologou KE et al. Alphasynuclein implicated in Parkinson's disease is present in extracellular biological fluids, including human plasma. FASEB J. 17(13), 1945-1947 (2003).

4 Mollenhauer B, El-Agnaf OM, Marcus K, Trenkwalder C, Schlossmacher MG. Quantification of alpha-synuclein in cerebrospinal fluid as a biomarker candidate: review of the literature and considerations for future studies. Biomark. Med. 4(5), 683-699 (2010).

5 Ueda K, Saitoh T, Mori H. Tissue-dependent alternative splicing of mRNA for NACP, the precursor of non-A beta component of Alzheimer's disease amyloid. Biochem. Biophys. Res. Commun. 205(2), 1366-1372 (1994).

6 Campion D, Martin C, Heilig R et al. The NACP/synuclein gene: chromosomal assignment and screening for alterations in Alzheimer disease. Genomics 26(2), 254-257 (1995).

7 Mollenhauer B, Cullen V, Kahn I et al. Direct quantification of CSF alpha-synuclein by ELISA and first cross-sectional study in patients with neurodegeneration. Exp. Neurol. 213(2), 315-325 (2008).

8 Tokuda T, Salem SA, Allsop D et al. Decreased alphasynuclein in cerebrospinal fluid of aged individuals and subjects with Parkinson's disease. Biochem. Biophys. Res. Commun. 349(1), 162-166 (2006).

9 Van Geel WJ, Abdo WF, Melis R, Williams S, Bloem BR, Verbeek MM. A more efficient enzyme-linked immunosorbent assay for measurement of alpha-synuclein in cerebrospinal fluid. J. Neurosci. Methods 168(1), 182-185 (2008).

10 Tokuda T, Qureshi MM, Ardah MT et al. Detection of elevated levels of alpha-synuclein oligomers in CSF from patients with Parkinson disease. Neurology 75(20), 1766-1772 (2010).

11 Parnetti L, Chiasserini D, Bellomo G et al. Cerebrospinal fluid Tau/alpha-synuclein ratio in Parkinson's disease and degenerative dementias. Mov. Disord. 26(8), 1428-1435 (2011).

12 Parnetti L, Farotti L, Eusebi P et al. Differential role of CSF alpha-synuclein species, tau, and Abeta42 in Parkinson's disease. Front. Aging Neurosci. 6, 53 (2014).

13 Reesink FE, Lemstra AW, Van Dijk KD et al. CSF alphasynuclein does not discriminate dementia with Lewy bodies from Alzheimer's disease. J. Alzheimers Dis. 22(1), 87-95 (2010).

14 Aerts MB, Esselink RA, Abdo WF, Bloem BR, Verbeek MM. CSF alpha-synuclein does not differentiate between parkinsonian disorders. Neurobiol. Aging 33(2), 430.e1-e3 (2012).

15 Park MJ, Cheon SM, Bae HR, Kim SH, Kim JW. Elevated levels of alpha-synuclein oligomer in the cerebrospinal fluid of drug-naive patients with Parkinson's disease. J. Clin. Neurol. 7(4), 215-222 (2011).

16 Aasly JO, Johansen KK, Bronstad G et al. Elevated levels of cerebrospinal fluid alpha-synuclein oligomers in healthy 
asymptomatic LRRK2 mutation carriers. Front. Aging Neurosci. 6, 248 (2014).

17 Tinsley RB, Kotschet K, Modesto D et al. Sensitive and specific detection of alpha-synuclein in human plasma. J. Neurosci. Res. 88(12), 2693-2700 (2010).

18 Duran R, Barrero FJ, Morales B, Luna JD, Ramirez M, Vives F. Plasma alpha-synuclein in patients with Parkinson's disease with and without treatment. Mov. Disord. 25(4), 489-493 (2010)

19 Tateno F, Sakakibara R, Kawai T, Kishi M, Murano T. Alpha-synuclein in the cerebrospinal fluid differentiates synucleinopathies (Parkinson disease, dementia with Lewy bodies, multiple system atrophy) from Alzheimer disease. Alzheimer Dis. Assoc. Disord. 26(3), 213-216 (2012).

20 Brighina L, Prigione A, Begni B et al. Lymphomonocyte alpha-synuclein levels in aging and in Parkinson disease. Neurobiol. Aging. 31(5), 884-885 (2010).

21 Su E, Bell MJ, Wisniewski SR et al. alpha-Synuclein levels are elevated in cerebrospinal fluid following traumatic brain injury in infants and children: the effect of therapeutic hypothermia. Dev. Neurosci. 32(5-6), 385-395 (2010).

22 Laske C, Fallgatter AJ, Stransky E, Hagen K, Berg D, Maetzler W. Decreased alpha-synuclein serum levels in patients with Lewy body dementia compared with Alzheimer's disease patients and control subjects. Dement. Geriatr. Cogn. Disord. 31(6), 413-416 (2011).

23 Wennstrom M, Surova Y, Hall S et al. Low CSF levels of both alpha-synuclein and the alpha-synuclein cleaving enzyme neurosin in patients with synucleinopathy. PLoS ONE 8(1), e53250 (2013).

24 Wang H, Wang K, Xu W et al. Cerebrospinal fluid alphasynuclein levels are elevated in multiple sclerosis and neuromyelitis optica patients during replase. J. Neurochem. 122(1), 19-23 (2012).

25 Bidinosti M, Shimshek DR, Mollenhauer B et al. Novel onestep immunoassays to quantify alpha-synuclein: applications for biomarker development and high-throughput screening. J. Biol. Chem. 287(40), 33691-33705 (2012).

26 Emmanouilidou E, Elenis D, Papasilekas T et al. Assessment of alpha-synuclein secretion in mouse and human brain parenchyma. PLoS ONE 6(7), e22225 (2011).

27 Lee HJ, Bae EJ, Jang A et al. Enzyme-linked immunosorbent assays for alpha-synuclein with species and multimeric state specificities. J. Neurosci. Methods 199(2), 249-257 (2011).

28 Kovacs GG, Wagner U, Dumont B et al. An antibody with high reactivity for disease-associated alpha-synuclein reveals extensive brain pathology. Acta Neuropathol. 124(1), 37-50 (2012).

29 Ohrfelt A, Grognet P, Andreasen N et al. Cerebrospinal fluid alpha-synuclein in neurodegenerative disorders-a marker of synapse loss? Neurosci. Lett. 450 (3), 332-335 (2009).

30 Kruse N, Vanmechelen E, Schlossmacher MG et al. Sensitive multiplex quantification of alpha-Synuclein, DJ-1, betaAmyloid 1-42 and Tau protein in human biological fluids based on chemiluminescence detection. Neurodegener. Dis. 11(Suppl. 1) (2013).
31 Kruse N, Schulz-Schaeffer WJ, Schlossmacher MG, Mollenhauer B. Development of electrochemiluminescencebased singleplex and multiplex assays for the quantification of alpha-synuclein and other proteins in cerebrospinal fluid. Methods 56(4), 514-518 (2012).

32 Kasuga K, Tokutake T, Ishikawa A et al. Differential levels of alpha-synuclein, beta-amyloid42 and tau in CSF between patients with dementia with Lewy bodies and Alzheimer's disease. J. Neurol. Neurosurg. Psychiatry 81(6), 608-610 (2010).

33 Hong Z, Shi M, Chung KA et al. DJ-1 and alpha-synuclein in human cerebrospinal fluid as biomarkers of Parkinson's disease. Brain 133(Pt 3), 713-726 (2010).

34 Mollenhauer B, Trautmann E, Taylor P et al. Total CSF alpha-synuclein is lower in de novo Parkinson patients than in healthy subjects. Neurosci. Lett. 532, 44-48 (2013).

35 Mollenhauer B, Locascio JJ, Schulz-Schaeffer W, SixelDoring F, Trenkwalder C, Schlossmacher MG. alphaSynuclein and tau concentrations in cerebrospinal fluid of patients presenting with parkinsonism: a cohort study. Lancet Neurol. 10(3), 230-240 (2011).

36 Korff A, Liu C, Ginghina C, Shi M, Zhang J, Alzheimer's Disease Neuroimaging I. alpha-Synuclein in cerebrospinal fluid of Alzheimer's disease and mild cognitive impairment. J. Alzheimers Dis. 36(4), 679-688 (2013).

37 Toledo JB, Korff A, Shaw LM, Trojanowski JQ, Zhang J. CSF alpha-synuclein improves diagnostic and prognostic performance of CSF tau and Abeta in Alzheimer's disease. Acta Neuropathol. 126(5), 683-697 (2013).

38 Hall S, Ohrfelt A, Constantinescu R et al. Accuracy of a panel of 5 cerebrospinal fluid biomarkers in the differential diagnosis of patients with dementia and/or Parkinsonian disorders. Arch. Neurol. 69(11), 1445-1452 (2012).

39 Slaets S, Vanmechelen E, Le Bastard N et al. Increased CSF alpha-synuclein levels in Alzheimer's disease: correlation with tau levels. Alzheimers Dement. 10(5, Suppl.), S290-S298 (2014).

40 Kang JH, Irwin DJ, Chen-Plotkin AS et al. Association of cerebrospinal fluid beta-amyloid 1-42, T-tau, P-tau181, and alpha-synuclein levels with clinical features of drug-naive patients with early Parkinson disease. JAMA neurol. 70(10), 1277-1287 (2013).

41 Mondello S, Constantinescu R, Zetterberg H, Andreasson U, Holmberg B, Jeromin A. CSF alpha-synuclein and UCH-L1 levels in Parkinson's disease and atypical parkinsonian disorders. Parkinsonism. Relat. Disord. 20(4), 382-387 (2014).

42 El-Agnaf OM, Irvine GB. Review: formation and properties of amyloid-like fibrils derived from alpha-synuclein and related proteins. J. Struct. Biol. 130(2-3), 300-309 (2000).

43 Sharon R, Bar-Joseph I, Frosch MP, Walsh DM, Hamilton JA, Selkoe DJ. The formation of highly soluble oligomers of alpha-synuclein is regulated by fatty acids and enhanced in Parkinson's disease. Neuron 37(4), 583-595 (2003).

44 Paleologou KE, Kragh CL, Mann DM et al. Detection of elevated levels of soluble alpha-synuclein oligomers in postmortem brain extracts from patients with dementia with Lewy bodies. Brain 132(Pt 4), 1093-1101 (2009). 
45 Klucken J, Outeiro TF, Nguyen P, Mclean PJ, Hyman BT. Detection of novel intracellular alpha-synuclein oligomeric species by fluorescence lifetime imaging. FASEB J. 20(12), 2050-2057 (2006).

46 El-Agnaf OM, Salem SA, Paleologou KE et al. Detection of oligomeric forms of alpha-synuclein protein in human plasma as a potential biomarker for Parkinson's disease. FASEB J. 20(3), 419-425 (2006).

47 Fujiwara H, Hasegawa M, Dohmae N et al. alpha-Synuclein is phosphorylated in synucleinopathy lesions. Nat. Cell. Biol. 4(2), 160-164 (2002).

48 Anderson JP, Walker DE, Goldstein JM et al. Phosphorylation of Ser-129 is the dominant pathological modification of alpha-synuclein in familial and sporadic Lewy body disease. J. Biol. Chem. 281(40), 29739-29752 (2006).

49 Games D, Seubert P, Rockenstein E et al. Axonopathy in an alpha-synuclein transgenic model of Lewy body disease is associated with extensive accumulation of C-terminaltruncated alpha-synuclein. Am. J. Pathol. 182(3), 940-953 (2013).

50 El-Agnaf OM, Walsh DM, Allsop D. Soluble oligomers for the diagnosis of neurodegenerative diseases. Lancet Neurol. 2(8), 461-462 (2003).

51 Bartels T, Choi JG, Selkoe DJ. alpha-Synuclein occurs physiologically as a helically folded tetramer that resists aggregation. Nature 477(7362), 107-110 (2011).

52 Gorostidi A, Bergareche A, Ruiz-Martinez J et al. Alphasynuclein levels in blood plasma from LRRK2 mutation carriers. PLoS ONE 7(12), e52312 (2012).

53 Lindersson E, Beedholm R, Hojrup P et al. Proteasomal inhibition by alpha-synuclein filaments and oligomers. J. Biol. Chem. 279(13), 12924-12934 (2004).

54 Unterberger U, Lachmann I, Voigtlander T et al. Detection of disease-associated alpha-synuclein in the cerebrospinal fluid: a feasibility study. Clin. Neuropathol. 33(5), 329-334 (2014).

55 Okochi M, Walter J, Koyama A et al. Constitutive phosphorylation of the Parkinson's disease associated alphasynuclein. J. Biol. Chem. 275(1), 390-397 (2000).

56 Chen L, Feany MB. Alpha-synuclein phosphorylation controls neurotoxicity and inclusion formation in a Drosophila model of Parkinson disease. Nat. Neurosci. 8(5), 657-663 (2005).

57 Foulds PG, Mitchell JD, Parker A et al. Phosphorylated alpha-synuclein can be detected in blood plasma and is potentially a useful biomarker for Parkinson's disease. FASEB J. 25(12), 4127-4137 (2011).

58 Wang Y, Shi M, Chung KA et al. Phosphorylated alphasynuclein in Parkinson's disease. Sci. Transl. Med. 4(121), 121ra120 (2012).

59 Fernandez E, Garcia-Moreno JM, Martin De Pablos A, Chacon $J$. May the evaluation of nitrosative stress through selective increase of 3-nitrotyrosine proteins other than nitroalbumin and dominant tyrosine-125/136 nitrosylation of serum alphasynuclein serve for diagnosis of sporadic Parkinson's disease? Antioxid. Redox. Signal. 19(9), 912-918 (2013).
60 Chavez J, Bajrami B, Copeland M et al. Development of quantitative methods to measure alpha-synuclein and related subspecies in CSF as candidate biomarkers for Parkinson's disease progression. Neurodegener. Dis. 11(Suppl. 1), (2013).

61 Van Dijk KD, Bidinosti M, Weiss A, Raijmakers P, Berendse HW, Van De Berg WD. Reduced alpha-synuclein levels in cerebrospinal fluid in Parkinson's disease are unrelated to clinical and imaging measures of disease severity. Eur. J. Neurol. 21(3), 388-394 (2014).

62 Blennow K, Wallin A, Hager O. Low frequency of postlumbar puncture headache in demented patients. Acta Neurol. Scand. 88(3), 221-223 (1993).

63 Braak H, Del Tredici K, Rub U, De Vos RA, Jansen Steur EN, Braak E. Staging of brain pathology related to sporadic Parkinson's disease. Neurobiol. Aging 24(2), 197-211 (2003).

64 Barbour R, Kling K, Anderson JP et al. Red blood cells are the major source of alpha-synuclein in blood. Neurodegener. Dis. 5(2), 55-59 (2008).

65 Scherzer CR, Grass JA, Liao Z et al. GATA transcription factors directly regulate the Parkinson's disease-linked gene alpha-synuclein. Proc. Natl Acad. Sci. USA 105(31), 10907-10912 (2008).

66 Mollenhauer B, Trautmann E, Otte B et al. alpha-Synuclein in human cerebrospinal fluid is principally derived from neurons of the central nervous system. J. Neural. Transm. 119(7), 739-746 (2012).

67 Mata IF, Shi M, Agarwal P et al. SNCA variant associated with Parkinson disease and plasma alpha-synuclein level. Arch. Neurol. 67(11), 1350-1356 (2010).

68 Besong-Agbo D, Wolf E, Jessen F et al. Naturally occurring alpha-synuclein autoantibody levels are lower in patients with Parkinson disease. Neurology 80(2), 169-175 (2013).

69 Devic I, Hwang H, Edgar JS et al. Salivary alpha-synuclein and DJ-1: potential biomarkers for Parkinson's disease. Brain 134(Pt 7), e178 (2011).

70 Bolstad N, Warren DJ, Nustad K. Heterophilic antibody interference in immunometric assays. Best Pract. Res. Clin. Endocrinol. Metab. 27(5), 647-661 (2013).

71 Sehlin D, Sollvander S, Paulie S et al. Interference from heterophilic antibodies in amyloid-beta oligomer ELISAs. J. Alzheimers Dis. 21(4), 1295-1301 (2010).

72 Bruggink KA, Kuiperij HB, Ekholm-Pettersson F, Verbeek MM. Detection of elevated levels of alpha-synuclein oligomers in CSF from patients with Parkinson disease. Neurology 77(5), 510; author reply 510-511 (2011).

73 Kasuga K, Nishizawa M, Ikeuchi T. alpha-synuclein as CSF and blood biomarker of dementia with Lewy bodies. Int. J. Alzheimers Dis. 2012, 437025 (2012).

74 Kapaki E, Paraskevas GP, Emmanouilidou E, Vekrellis $\mathrm{K}$. The diagnostic value of CSF alpha-synuclein in the differential diagnosis of dementia with Lewy bodies vs. normal subjects and patients with Alzheimer's disease. PLoS ONE 8(11), e81654 (2013).

75 Teunissen CE, Tumani H, Bennett JL et al. Consensus Guidelines for CSF and Blood Biobanking for CNS Biomarker studies. Mult. Scler. Int. 2011, 246412 (2011). 
76 Vakharia VN, Lote H. Introduction of Sprotte needles to a single-centre acute neurology service: before and after study. JRSM Short Rep. 3(12), 82 (2012).

77 Del Campo M, Mollenhauer B, Bertolotto A et al. Recommendations to standardize preanalytical confounding factors in Alzheimer's and Parkinson's disease cerebrospinal fluid biomarkers: an update. Biomark. Med. 6(4), 419-430 (2012).

78 Noguchi-Shinohara M, Tokuda T, Yoshita M et al. CSF alpha-synuclein levels in dementia with Lewy bodies and Alzheimer's disease. Brain Res. 1251, 1-6 (2009).

79 Mignini F, Bronzetti E, Felici L et al. Dopamine receptor immunohistochemistry in the rat choroid plexus. J. Auton. Pharmacol. 20(5-6), 325-332 (2000).

80 Wennstrom M, Londos E, Minthon L, Nielsen HM. Altered CSF orexin and alpha-synuclein levels in dementia patients. J. Alzheimers. Dis. 29(1), 125-132 (2012).

81 Kang JE, Lim MM, Bateman RJ et al. Amyloid-beta dynamics are regulated by orexin and the sleep-wake cycle. Science 326(5955), 1005-1007 (2009).

82 Bateman RJ, Wen G, Morris JC, Holtzman DM. Fluctuations of CSF amyloid-beta levels: implications for a diagnostic and therapeutic biomarker. Neurology 68(9), 666-669 (2007).

83 Spies PE, Slats D, Rikkert MG, Tseng J, Claassen JA, Verbeek MM. CSF alpha-synuclein concentrations do not fluctuate over hours and are not correlated to amyloid beta in humans. Neurosci. Lett. 504(3), 336-338 (2011).

84 Spies PE, Melis RJ, Sjogren MJ, Rikkert MG, Verbeek MM. Cerebrospinal fluid alpha-synuclein does not discriminate between dementia disorders. J. Alzheimers Dis. 16(2), 363-369 (2009).

\footnotetext{
Affiliations

\section{Anja Hviid Simonsen}

Memory Disorders Research Group, Department of Neurology, Rigshospitalet, Copenhagen University Hospital, Copenhagen, Denmark

\section{Bea Kuiperij}

Department of Neurology, Department of Laboratory Medicine, Donders Institute for Brain, Cognition \& Behaviour, Radboud University Medical Center, Nijmegen, The Netherlands

Omar Mukhtar Ali El-Agnaf

Department of Biochemistry, Faculty of Medicine \& Health Sciences, United Arab Emirates University, Al Ain, United Arab Emirates and

Faculty of Medicine, King Abdulaziz University, Jeddah, Saudi Arabia Sebastian Engelborghs Reference Center for Biological Markers of Dementia (BIODEM), Institute Born-Bunge, University of Antwerp \& Department of Neurology \& Memory Clinic, Hospital Network Antwerp (ZNA) Middelheim and Hoge Beuken, Antwerp, Belgium

Sanna-Kaisa Herukka

Institute of Clinical Medicine - Neurology University of Eastern Finland School of Medicine, Kuopio, Finland
}

85 Shi M, Bradner J, Hancock AM et al. Cerebrospinal fluid biomarkers for Parkinson disease diagnosis and progression. Ann. Neurol. 69(3), 570-580 (2011).

86 Herbert MK, Aerts MB, Beenes M et al.CSF neurofilament light chain but not FLT3 ligand discriminates Parkinsonian disorders. Front Neurol. 6, 91 (2015).

87 Abdo WF, Bloem BR, Van Geel WJ, Esselink RA, Verbeek MM. CSF neurofilament light chain and tau differentiate multiple system atrophy from Parkinson's disease. Neurobiol. Aging 28(5), 742-747 (2007).

88 Giasson BI, Forman MS, Higuchi M et al. Initiation and synergistic fibrillization of tau and alpha-synuclein. Science 300(5619), 636-640 (2003).

89 Shi M, Furay AR, Sossi V et al. DJ-1 and alphaSYN in LRRK2 CSF do not correlate with striatal dopaminergic function. Neurobiol. Aging 33(4), 836 e835-e837 (2012).

90 Mollenhauer B, Trautmann E, Sixel-Doring F et al. Nonmotor and diagnostic findings in subjects with de novo Parkinson disease of the DeNoPa cohort. Neurology 81(14), 1226-1234 (2013).

91 Parkinson Progression Marker I. The Parkinson Progression Marker Initiative (PPMI). Prog. Neurobiol. 95(4), 629-635 (2011).

92 Jellinger KA, Attems J. Neuropathological evaluation of mixed dementia. J. Neurol. Sci 257(1-2), 80-87 (2007).

93 Slaets S, Le Bastard N, Theuns J et al. Amyloid pathology influences abeta1-42 cerebrospinal fluid levels in dementia with lewy bodies. J. Alzheimers Dis. 35(1), 137-146 (2013).

94 Parnetti L, Castrioto A, Chiasserini D et al. Cerebrospinal fluid biomarkers in Parkinson disease. Nat. Rev. Neurol. 9(3), 131-140 (2013).

\section{Lucilla Parnetti}

Centro Disturbi della Memoria- Unità Valutativa Alzheimer, Clinica Neurologica, Università di Perugia, Italy

Irena Rektorova

Applied Neuroscience Research Group, CEITEC MU, Masaryk University, Brno, Czech Republic

\section{Eugeen Vanmechelen}

ADx NeuroSciences, VIB-Bioincubator, Technologiepark Zwijnaarde 4, 9052 Ghent, Belgium

\section{Elisabeth Kapaki}

National \& Kapodistrian University of Athens, School of Medicine, 1st Department of Neurology, Eginition Hospital, Athens, Greece

\section{Marcel Verbeek}

Department of Neurology, Department of Laboratory Medicine, Donders Institute for Brain, Cognition \& Behaviour, Radboud University Medical Center, Nijmegen, The Netherlands

\section{Brit Mollenhauer}

Paracelsus-Elena-Klinik, Kassel \& University Medical Center

(Departments of Neuropathology \& Neurosurgery), Georg-August University Goettingen, Germany 